\title{
Inverse Receptor Agonist
}

National Cancer Institute

\section{Source}

National Cancer Institute. Inverse Receptor Agonist. NCI Thesaurus. Code C154901.

A class of substances that binds to a receptor at the same binding site as an agonist, but induces a biological response opposite to that agonist. 